\title{
MODEL INFORMASI KEPUTUSAN BERBASIS TOPSIS APLIKASI ANDROID
}

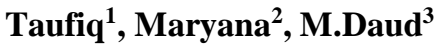 \\ ${ }^{1,3}$ Teknik Elektro, ${ }^{2}$ Teknik Informatika \\ Universitas Malikussaleh Lhokseumawe Aceh \\ taufiq.te@unimal.ac.id
}

\begin{abstract}
Information Technology in spatial data processing has developed to a point where these results are in line with the application challenges required by natural resource management. In addition, the internet, geomatics, and telecommunications are rapidly changing the way natural resources are managed and protected. These provide more accurate and up-to-date information and are quickly available to users. Regional potential is a product that exists in an area that can be developed and is able to provide benefits to the local community and can be used as a supporter of the national economy. This understanding gives the connotation that optimal management planning is needed in order to achieve the intended expectations, so this decision support system is presented in a simple form for easy access on Android smartphone devices. Applications are made with Eclipse as an editor as well as compile and builder and SQLite for the application database.
\end{abstract}

Keywords: Information, Decision, Android, Model

\section{PENDAHULUAN}

Komoditas unggulan yang banyak tapat di Aceh ialah perkebunan, perikanan, pertambangan, dan persawahan sepanjang daerah Aceh. Basarkan data diatas, maka diperlukan perencanaan dan pengelolaan tentang potensi sumber daya alam sebagai salah satu faktor utama dalam peningkatan pengembangan perekonomian khususnya di Aceh dan Indonesia umumnya. Pengelolaan industri di provinsi Aceh masih didominasi oleh usaha biasa. Hal ini memberi dampak antara lain bahwa para daerah tidak mendapatkan informasi yang cukup berkaitan dengan permintaan pasar maupun harga pasar.

Model informasi untuk memperoleh profil potensi daerah telah banyak dikembangkan. Salah satunya barubaru ini Taufiq (2017) telah mengembangkan Model Informasi Desa Desa. Shaparev dan Yakubailik (2016) menggunakan system informasi pemetaan web untuk mendukung pengelolaan regional. Yao et al, (2017) juga mengajukan system informasi basarkan system informasi geografis (GIS) untuk pengalokasian potensi daerah. Namun perlu dicatat bahwa penggunaan system informasi demikian ini lebih banyak ditujukan untuk pemberian deskripsi profil suatu daerah. Walaupun informasi ini dapat dipakai sebagai dasar untuk pengambilan keputusan, tetapi Model tidak secara langsung dapat menghasilkan keputusan. Permasalahan bagaimana faktor penentuan potensi daerah dengan menggunkan teknologi mobile computing dengan cepat dan tepat dalam menentukan potensi suatu daerah tersebut. Smarphone merupakan salah satu kemajuan teknologi yang begitu berkembang saat ini. Seiring kemajuan teknologi smartphone beberapa kegiatan yang dapat dilakukan oleh komputer semisalnya kegiatan browsing internet, pencarian, dan lainya dapat diganti dengan penggunaan smartphone tersebut dengan dukungan pengembangan teknologi sistem operasi yang terus berkembang semisalnya android. Berdasarkan permasalah yang timbul dalam penentuan haraga beli biji kopi, yang mana dapat dibuata sebuah sistem pendukung keputusan yang didukung oleh teknologi mobile. Sehingga perlu dilakukan untuk penerapan teknologi mobile computing untuk membuat aplikasi yang dapat menentukan potensi daerah, menggunakan aplikasi berbasis bagi pengguna serta pemakaiannya pada perangkat mobile android. Diharapkan tujuan dari penelitian ini dapat membuat sebuah mobile application sistem pendukung keputusan penentuan potensi daerah berbasis android. Pemanfaatnya juga sangat diperlukan karena dengan adanya aplikasi sistem pendukung keputusan penentuan potensi daerah, diharapkan akan memberikan kemudahan mengenai cara penetuan potensi suatu daerah. Kemudian dapat melakukan banyak hal dalam berbagai macam metode yang digunakan diharapkan dapat memberikan kemudahan yang sesuai dalam menetukan kriteria-kriteria penilai untuk penentuan potensi daerah. Salah satu yang paling penting adalah dapat dijadikan sebagai sumber data untuk pendukung keputusan bagi masyarakat dalam menentukan perioritas dimasa akan datang.

\section{KAJIAN TEORI}

Menurut Moore dan Chang dalam buku Principle of Service Marketing, yang diterjemahkan oleh Turban,dkk, (1995), menyebutkan bahwa "sistem pendukung keputusan dapat digambarkan sebagai sistem yang berkemampuan mendukung analisis ad hoc data, dan pemodelan keputusan, berorientasi keputusan, orientasi perencanaan masa depan, dan digunakan pada saatsaat yang tidak biasa". TOPSIS (Technique For Others Reference by Similarity to Ideal Solution) adalah salah satu metode pengambilan keputusan multikriteria yang pertama kali diperkenalkan oleh Yoon dan Hwang (1981). TOPSIS menggunakan prinsip bahwa alternatif 
yang terpilih harus mempunyai jarak terdekat dari solusi ideal positif dan terjauh dari solusi ideal negatif dari sudut pandang geometris dengan menggunakan jarak Euclidean untuk menentukan kedekatan relatif dari suatu alternatif dengan solusi optimal.Langkah-langkah yang dilakukan dalam menyelesaikan suatu permasalahan menggunakan metode TOPSIS adalah sebagai berikut:

a. Menggambarkan alternatif (m) dan kriteria (n) k e dalam sebuah matriks, dimana $\mathrm{Xij}$ adalah pengukuran pilihan dari alternatif kei dan kriteria ke-j.Matriks ini dapat dilihat pada persamaan berikut :

$$
D=\left[\begin{array}{ccc}
X 11 & X 12 & X 13 \\
X 21 & X 22 & X 23 \\
X i 1 & X i 2 & X i 3
\end{array}\right]
$$

b. Membuat matriks $R$ yaitu matriks keputusan ternormalisasi Setiap normalisasi dari nilai rij dapat dilakukan dengan perhitungan menggunakan persamaan berikut :

$$
R i j=\frac{\mathrm{Xij}}{\sqrt{\sum_{i=1}^{m} X i j}}
$$

c. Membuat pembobotan pada matriks yang telah dinormalisasi Setelah dinormalisasi, setiap kolom pada matriks $\mathrm{R}$ dikalikan dengan bobot-bobot (wj) untuk menghasilkan matriks pada persamaan berikut:

$$
D=\left[\begin{array}{ccc}
W 1 r 11 & W 1 r 12 & W n r n \\
W 2 r 21 & \ldots & \ldots \\
W j r m 1 & W j r m 2 & \text { Wjrmm }
\end{array}\right]
$$

d. Menentukan nilai solusi ideal positif dan solusi ideal negatif. Solusi ideal dinotasikan A+, sedangkan solusi ideal negatif dinotasikan A-. Persamaan untuk menentukan solusi ideal dapat dilihat pada persamaan berikut:

A+

$=\left\{(\max V i j \mid j \in J),\left(\min V i j \mid j \in j^{\prime}\right), i=1,2,3, \ldots, m\right\}$

$=V 1+V 2+, \ldots, V n+\}$

A-

$=\left\{(\max V i j \mid j \in J),\left(\min V i j \mid j \in j^{\prime}\right), i=1,2,3, \ldots, m\right\}$

$=V 1-V 2-, \ldots, V n-\}$

$J=\{j$

$=1,2,3, \ldots . n$ dan $j$ merupqkan benefit kriteria $\}$

$J^{\prime}=\{j$

$=1,2,3, \ldots n$ dan $j$ merupqkan cost kriteria $\}$

e. Menghitung separation measure. Separation measure ini merupakan pengukuran jarak dari suatu alternatif ke solusi ideal positif dan solusi ideal negatif.

1. Perhitungan solusi ideal positif dapat dilihat pada persamaan berikut :

$S i^{+}=\sqrt{\sum_{i=1}^{n}(V i j-V j+)^{2}}$ Dengan $\mathrm{i}=1,2,3, \ldots, \mathrm{m}$

2. Perhitungan solusi ideal negatif dapat dilihat pada persamaan berikut :

$$
S i^{+}=\sqrt{\sum_{i=1}^{n}(V i j-V j-)^{2}}
$$

Dengan $\mathrm{i}=1,2,3, \ldots, \mathrm{m}$

f. Menghitung nilai preferensi untuk setiap alternat if. Untuk menentukan ranking tiap-tiap alternatif yang ada maka perlu dihitung terlebih dahulu nilai preferensi dari tiap alternatif. Perhitungan nilai preferensi dapat dilihat melalui persamaan tujuh.

$$
\mathrm{Ci}+=\frac{S i^{-}}{S i^{+}+S i^{-}}
$$

Dimana $0<\mathrm{C}_{1}+<1$ dan $\mathrm{i}=1,2,3, \ldots, \mathrm{m}$

Eclipse adalah sebuah IDE (Integrated Development Environment) untuk mengembangkan perangkat lunak dan dapat dijalankan di semua platform (platformindependent).

\section{METODELOGI PENELITIAN}

Adapun metodelogi yang digunakan adalah sebagai berikut:

a. Pengumpulan data

Pengumpulan data dilakukan dengan mencari informasi buku dan dari internet.

b. Perancanagan

Pada tahapan ini dilakukan dengan perancanagn tampilan disetiap halaman untuk aplikasi.

c. Pembuatan program/ coding

Dalam pembuatan program aplikasi ini menggunakan software Android SDK Windows, dan Eclipse Juno untuk pecodingan pembuatan aplikasi.

d. Uji coba aplikasi

Untuk dapat menjalankan aplikasi dibutuhkan emulator sebagai perangkat lunak, yaitu AVD manager, yang selanjutnya aplikasi disiapkan dalam paket guna dapat di install pada perangkat mobile android untuk pengujian.

\section{PEMBAHASAN}

\section{Alternatif dan Kriteria}

Table 1. Alternatif

\begin{tabular}{|l|l|l|}
\hline Id & Alternatif & \multicolumn{1}{|c|}{ Keterangan } \\
\hline A1 & 30.000 & Mutu (Grade) 1 \\
\hline A2 & 28.000 & Mutu (Grade) 2 \\
\hline A3 & 26.000 & Mutu (Grade) 3 \\
\hline A4 & 24.000 & Mutu (Grade) 4a \\
\hline A5 & 23.500 & Mutu (Grade) 4b \\
\hline A6 & 22.000 & Mutu (Grade) 5 \\
\hline A7 & 20.000 & Mutu (Grade) 6 \\
\hline
\end{tabular}

Table 2 Kriteria

\begin{tabular}{|c|l|l|}
\hline Id & \multicolumn{1}{|c|}{ Keterangan } & \multicolumn{1}{|c|}{ Keterangan } \\
\hline K1 & Serangga hidup & Benefit \\
\hline K2 & Berbau/ bau kepang & Benefit \\
\hline K3 & Kadar air & Benefit \\
\hline K4 & Kadar kotoran & Benefit \\
\hline K5 & Nilai cacat & Benefit \\
\hline K6 & Ukuran biji & Benefit \\
\hline
\end{tabular}


Tabel 3 Alternatif Kriteria (Nilai)

\begin{tabular}{|c|c|c|c|c|c|c|c|}
\hline \multirow{2}{*}{ Kriteria } & \multicolumn{7}{|c|}{ Alternatif } \\
\cline { 2 - 8 } & A1 & A2 & A3 & A4 & A5 & A6 & A7 \\
\hline K1 & 90 & 80 & 70 & 60 & 55 & 35 & 25 \\
\hline K2 & 80 & 70 & 60 & 50 & 45 & 30 & 20 \\
\hline K3 & 100 & 90 & 80 & 70 & 65 & 50 & 40 \\
\hline K4 & 90 & 80 & 70 & 60 & 55 & 35 & 25 \\
\hline K5 & 100 & 90 & 80 & 70 & 65 & 50 & 40 \\
\hline K6 & 80 & 70 & 60 & 50 & 45 & 30 & 20 \\
\hline
\end{tabular}

Membuat Keputusan Ternormalisasi

\begin{tabular}{|c|c|c|c|c|c|c|}
\multicolumn{7}{c}{ Tabel 4 Keputusan ternormalisasi } \\
\hline A1 & 0.5225 & 0.5384 & 0.5098 & 0.5225 & 0.5098 & 0.5384 \\
\hline A2 & 0.4644 & 0.4711 & 0.4588 & 0.4644 & 0.4588 & 0.4711 \\
\hline A3 & 0.4064 & 0.4038 & 0.4079 & 0.4064 & 0.4079 & 0.4038 \\
\hline A4 & 0.3483 & 0.3365 & 0.3569 & 0.3483 & 0.3569 & 0.3365 \\
\hline A5 & 0.3193 & 0.3029 & 0.3314 & 0.3193 & 0.3314 & 0.3029 \\
\hline A6 & 0.2032 & 0.2356 & 0.1784 & 0.2032 & 0.1784 & 0.2356 \\
\hline A7 & 0.1451 & 0.1683 & 0.1275 & 0.1451 & 0.1275 & 0.1683 \\
\hline
\end{tabular}

Tabel 5 Data ternormalisasi

\begin{tabular}{|c|c|c|c|c|c|c|}
\hline & K1 & K2 & K3 & K4 & K5 & K6 \\
\hline A1 & 2.0898 & 2.6922 & 2.0393 & 1.5674 & 1.5294 & 1.076886 \\
\hline $\mathbf{A 2}$ & 1.8576 & 2.3557 & 1.8353 & 1.3932 & 1.3765 & 0.942275 \\
\hline $\mathbf{A 3}$ & 1.6254 & 2.0192 & 1.6314 & 1.2191 & 1.2236 & 0.807664 \\
\hline $\mathbf{A 4}$ & 1.3932 & 1.6826 & 1.4275 & 1.0449 & 1.0706 & 0.673054 \\
\hline $\mathbf{A 5}$ & 1.2771 & 1.5144 & 1.3255 & 0.9578 & 0.9941 & 0.605748 \\
\hline $\mathbf{A 6}$ & 0.8127 & 1.1778 & 0.7137 & 0.6095 & 0.5353 & 0.471138 \\
\hline $\mathbf{A 7}$ & 0.5805 & 0.8413 & 0.5098 & 0.4354 & 0.3824 & 0.336527 \\
\hline
\end{tabular}

Membuat Pembobota Pada Metrik Ternormalisasi

Tabel 6 Data normalisasi berbobot

\begin{tabular}{|c|c|c|c|c|c|c|}
\hline & C1 & C2 & C3 & C4 & C5 & C6 \\
\hline A1 & 2.0898 & 2.6922 & 2.0393 & 1.5674 & 1.5294 & 1.076886 \\
\hline A2 & 1.8576 & 2.3557 & 1.8353 & 1.3932 & 1.3765 & 0.942275 \\
\hline A3 & 1.6254 & 2.0192 & 1.6314 & 1.2191 & 1.2236 & 0.807664 \\
\hline A4 & 1.3932 & 1.6826 & 1.4275 & 1.0449 & 1.0706 & 0.673054 \\
\hline A5 & 1.2771 & 1.5144 & 1.3255 & 0.9578 & 0.9941 & 0.605748 \\
\hline A6 & 0.8127 & 1.1778 & 0.7137 & 0.6095 & 0.5353 & 0.471138 \\
\hline A7 & 0.5805 & 0.8413 & 0.5098 & 0.4354 & 0.3824 & 0.336527 \\
\hline
\end{tabular}

\section{Menentukan Nilai Solusi Positif dan Negatif}

Tabel 7 Nilai maksimal dan minimal

\begin{tabular}{|c|c|c|c|c|c|c|}
\hline & C1 & C2 & C3 & C4 & C5 & C6 \\
\hline A1 & 2.0898 & 2.6922 & 2.0393 & 1.5674 & 1.5294 & 1.076886 \\
\hline A2 & 1.8576 & 2.3557 & 1.8353 & 1.3932 & 1.3765 & 0.942275 \\
\hline A3 & 1.6254 & 2.0192 & 1.6314 & 1.2191 & 1.2236 & 0.807664 \\
\hline A4 & 1.3932 & 1.6826 & 1.4275 & 1.0449 & 1.0706 & 0.673054 \\
\hline A5 & 1.2771 & 1.5144 & 1.3255 & 0.9578 & 0.9941 & 0.605748 \\
\hline A6 & 0.8127 & 1.1778 & 0.7137 & 0.6095 & 0.5353 & 0.471138 \\
\hline A7 & 0.5805 & 0.8413 & 0.5098 & 0.4354 & 0.3824 & 0.336527 \\
\hline Max & 2.0898 & 2.6922 & 2.0393 & 1.5674 & 1.5294 & 1.076886 \\
\hline Min & 0.5805 & 0.8413 & 0.5098 & 0.4354 & 0.3824 & 0.336527 \\
\hline
\end{tabular}

\section{Menghitung Speration Measure}

Tabel 8 Nilai alternatif solusi ideal positif

\begin{tabular}{|c|c|}
\hline & Nilai \\
\hline D1+ & 0,0 \\
\hline D2+ & 0,544192 \\
\hline D3+ & 1,088385 \\
\hline D4+ & 1,632577 \\
\hline D5+ & 1,904673 \\
\hline D6+ & 2,806397 \\
\hline D7+ & 3,382769 \\
\hline
\end{tabular}

Tabel 9 Nilai alternatif solusi ideal negatif

\begin{tabular}{|c|c|}
\hline & Nilai \\
\hline D1- & 3,382769 \\
\hline D2- & 2,806397 \\
\hline D3- & 1,904673 \\
\hline D4- & 1,632577 \\
\hline D5- & 1,088385 \\
\hline D6- & 0,544192 \\
\hline D7- & 0,0 \\
\hline
\end{tabular}

\section{Use Case Diagram}

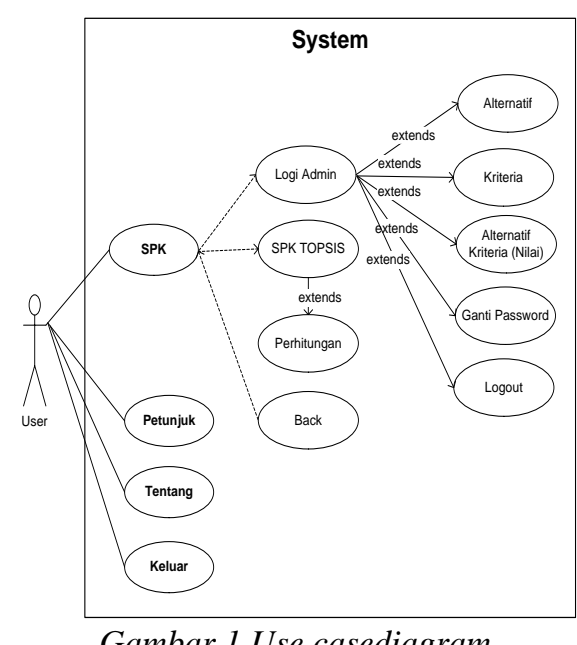

Gambar 1.Use casediagram 


\section{Sequence Diagram}

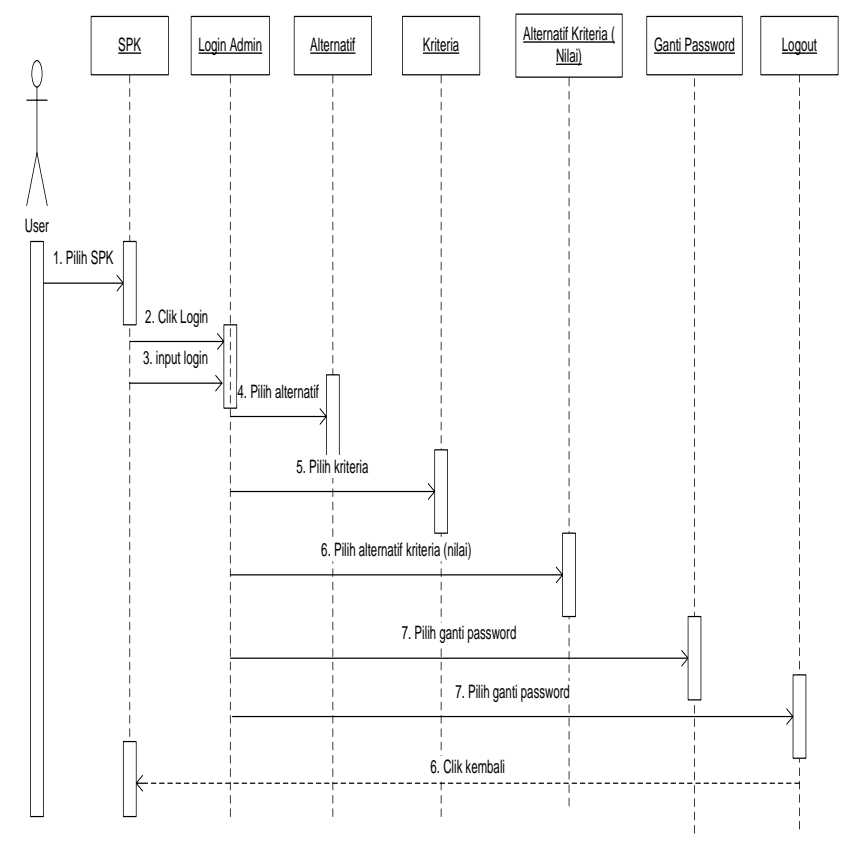

Gambar 2 Sequence diagram SPK

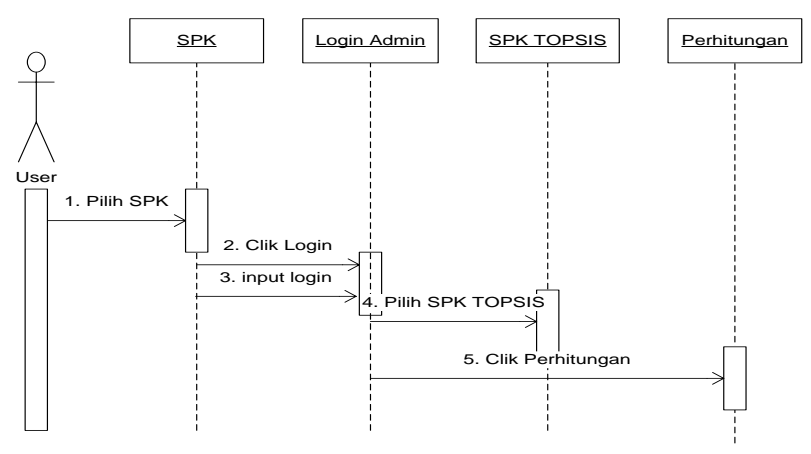

Gambar 3. Sequence diagram SPK TOPSIS

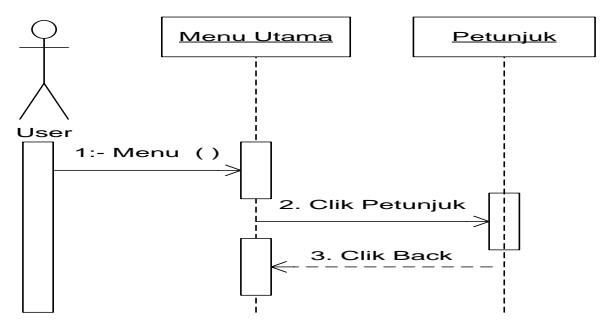

Gambar 4. Sequence diagram petunjuk

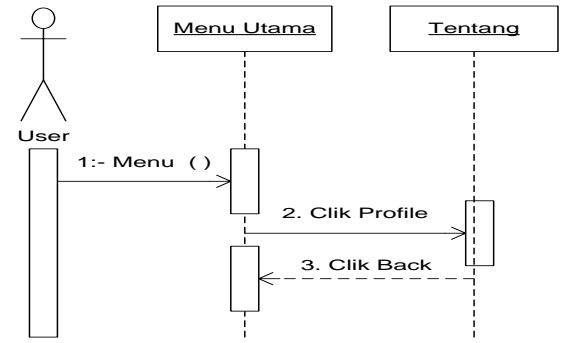

Gambar 5. Sequence diagram tentang

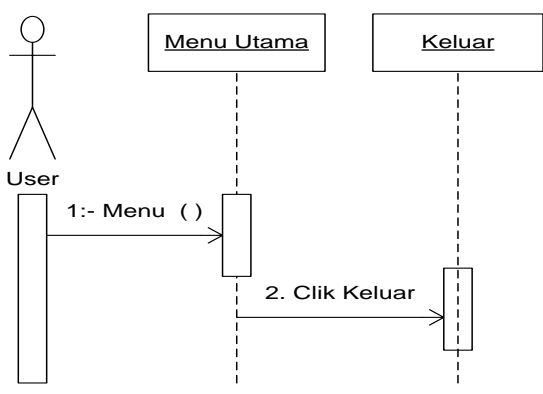

Gambar 6. Sequence diagram keluar

\section{IMPLEMENTASI}

\subsection{Pengujian Aplikasi}

Pengujian yang dilakukan dengan menguji dengan meng-compile program agar dapat berjalan dalam emulator dan mem-package aplikasi dalam bentuk file apk untuk dapat diinstallkan pada smartphone atau perangkan seluler lainya yang mempunyai operating system $(O S)$ android. Smartphoneandroid yang digunakan versi 4.4.2 (Kitkat) dan juga bias dijalan pada versi minimal 4.2 (Jellybeand), Berdasarkan hasil pengujian dengan kasus sample uji yang telah dilakukan maka hasil pengujian dapat memberikan kesimpulan bahwa aplikasi sistem pendukung keputusan penentuan harga biji kopi menggunakan metode topsis berbasis android dapat berjalan dengan baik dan sesuai kebutuhannya dan juga dapat menghasilkan output yang diharapkan, walaupun terbatas hanya pada pengujian yang minimal. Meski pengujian yang dilakukan masih terbilang minimal namun perangkat lunak bebas dari kesalahan sintak dan secara fungsional dapat mengeluarkan hasil yang sesuai dengan yang diharapkan dan sudah dapat mewakili pengujian fungsionalitas yang lainnya.

Berdasarkan pengujian yang dilakukan terhadap aplikasi sistem pendukung keputusan menggunakan metode topsis berbasis android, maka pengujianya dilakukan dengan dua jenis yaitu pada emulator android dari aplikasi eclipse dan pada smartphoneandroid, adapun hasil pengujian adalah sebagai berikut : 


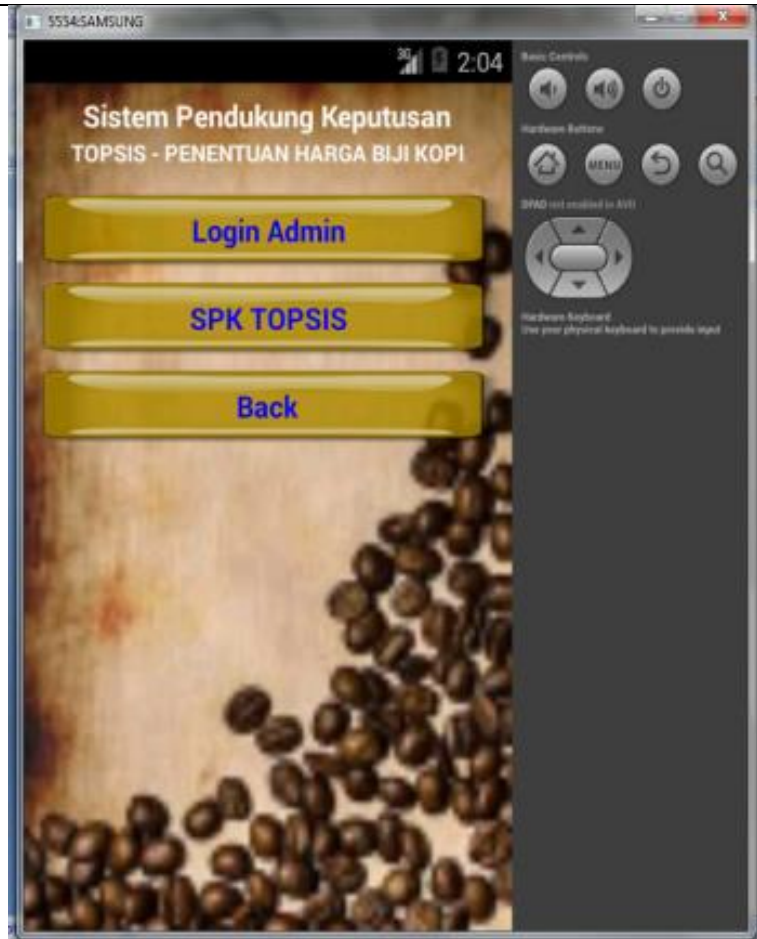

Gambar 7 Pengujian submenu SPK

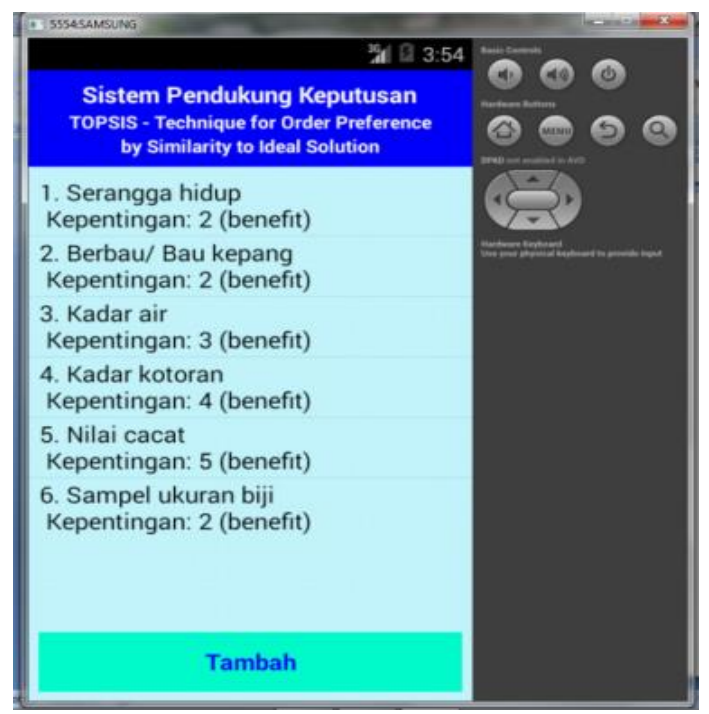

Gambar 8 Pengujian kriteria

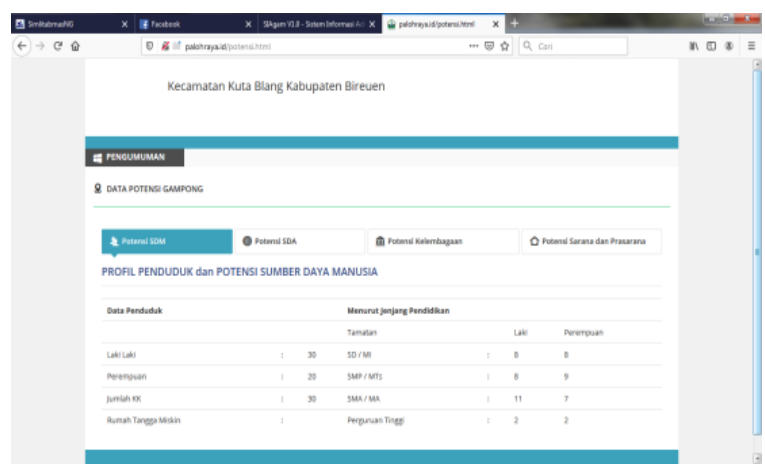

Gambar 9. Pengujian Hasil Tampilan

\section{KESIMPULAN}

\section{Kesimpulan}

Berdasarkan bahasan sebelumnya maka diberikan kesimpulan sebgai berikut:

a. Aplikasi sistem pendukung keputusan penentuan harga biji kopi menggunakan metode topsis berbasis android yang dibuat sesuai dengan pengembangan sistem berdasarkan permasalahan serta analisa sistem pada PT. Tri Maju Pondok Baru Kabupaten Bener Meriah,

b. Aplikasi ini dibuat sebagai sebuah aplikasi mobileandroid yang dipergunakan untuk melakukan proses perhitungan metode topsis dalam sistem pendukung keputusan.

c. Aplikasi ini diharapkan dapat dijadikan media informasi dan pembelajaran sehingga dapat meningkatkan minat pemakai secara umum dan khususnya pihak PT. Tri Maju dalam penunjang sistem pendukung keputusan.

d. Prosedur penilaian yang dibaut dalam aplikasi sesuai dengan referensi ketuntuan Stanadar Nasional Indonesia (SNI) dalam penentuan kualitas mutu biji kopi, yang tak terlepas dari prosedur ketentuan ICO (International Coffe Organotiation) sehingga data yang dimasukan kedalam aplikasi sesuai dengan ketentuan pada umunya.

e. Aplikasi ini dirancang dengan tampilan rancangan antar muka yang mudah dimengerti dan dipahami dengan penyedian menu-menu yang menarik.

f. Aplikasi ini dibuat pada platformandroid dengan versi target android 4.4.2 (Kitkat) dengan tampilan resolusi layar emulator 480 x 800 hdpi dengan CPU ARM (armeiabi v-7a) maupun Intel Atom x86.

\section{Saran}

Penulis berharap pengembangan dan modifikasi dalam beberapa hal seperti tampilan pada aplikasi ini harus lebih variatif dan lebih bagus lagi, serta diharapkan pengembangan dan penyempurnaan pada fitur-fitur tambahannya, karena penulis menyadari bahwa aplikasi resep masakan khas aceh masih jauh dari sempurna. Dalam pembangunan aplikasi sistem pendukung keputusan penentuan harga biji kopi menggunakan metode topsis berbasis android yang masih banyak kekurangan. Oleh karena itu perlu dilakukan pengembangan dan penyempurnaan lebih lanjut. Adapun saran agar aplikasi ini bisa berfungsi dengan baik lebih optimal dan lebih menarik sebagai berikut:

a. Pada desain interface (antar muka) dapat diberikan tampilan yang lebih menarik dan interaktife serta menu-menu interaktif lainya seperti audio.

b. Menambahkan lebih banyak fitur menu, bukan perhitungan spk topsis, tapi juga ada dukungan video-video tutorial.

c. Aplikasi dikembangkan dapat berjalan secara online pada web server sehingga dapat lebih mudah dikembangkan. 


\section{DAFTAR PUSTAKA}

[1]. Ardiansyah, F, 2011, Pengenalan Dasar Android Programming, Birainara, Depok

[2]. Haryanto, B, 2004, Rekayasa Sistem Berorientasi Objek, Informatika, Bandung

[3]. Huda, Akbarul. A, 2012, Live Coding, Edisi 1, Andi Yogyakarta, Yagyakarta

[4]. Taufiq, Herman Mawengkang, M.Zarlis, Suwilo. Charakter Variable Model Determination of Regional Potential

[5]. Decisions Using Driven Data. International Journal is Recent Technology and Engineering IJRTE ISSN 2277-3878, Volume 8 issue 3S October 2019

[6]. Taufiq, Herman Mawengkang, M.Zarlis, Maryana, Facrurazi, Sulhatun. Dissemination Model of Android Based Village Information Technology for Communities in Bireuen District. International Journal is Recent Technology and Engineering IJRTE ISSN 2277-3878, Volume 8 issue 6S5 April 2019

[7]. Taufiq, Herman Mawengkang, M.Zarlis, Saib Suwilo Android Based Rural Decision Support Information System Model. International. Journal is Recent Technology and Engineering IJRTE ISSN 2277-3878, Volume 8 issue 3S October 2019

[8]. Taufiq, Maryana. M.Daud. Sistem Informasi Pedesaan Terintegrasi Berbasis Android 978602-464-012-5 Unimal Press

[9]. Taufiq, Herman Mawengkang, M.Zarlis, Saib Suwilo. Integrated Rural Descision Support System Model Base on Android. ECCSAM 2018. IOP Conf Series of Physics. Conf Series $1255 \quad$ (2019) 012082 doi.10.1088/17426596/1255/1//102082.

[10]. Taufiq, Herman Mawenkang, M.Zarlis, Saib Suwilo, Model Of Election Of The Best University In Village. Icsecs 2019 UMP Pahang Malaysia. 